\title{
Plan de marketing en el sector salud. Ciudad de Cuenca, Ecuador
}

\author{
Marketing plan in the health sector. City of Cuenca, Ecuador
}

Alberto Esteban Mogrovejo Lazo. ${ }^{1}$, Kléber Antonio Luna Altamirano. ${ }^{2}$, Jorge Edwin Ormaza Andrade. ${ }^{3}$, Prissila Germania Castro Vazquez. ${ }^{4}$ \& Alicia Mariela Torres Beltrán. ${ }^{5}$

Recibido: 10-04-2019 / Revisado: 25-04-2019 / Aceptado: 05-05-2019 / Publicado: 16-05-2019

\begin{abstract}
.
DOI: https://doi.org/10.33262/cienciadigital.v3i2.3.483

Currently the Hospital del Río - Hospirio S.A, it is a private institution that has the greatest dimension in building and capacity to house patients in the Zone 6 Region of Ecuador; therefore, patients are not only located in the urban area of the city of Cuenca, they also exist in the rural area of Cuenca, from the province of Azuay and other provinces such as Cañar, El Oro, Loja, Morona Santiago and Zamora Chinchipe. It has first-class facilities, it also has advanced technology in the branch of medicine to provide quality services, with responsibility and trust. However, the institution has tried to promote management plans, for the entry of patients per year, and obtain a flow of income / expenses, which allows to project its annual management, but, the percentage between the budgeted and the real has had differences, obtaining a low entrance of patients, which leads to adjust the expenses for the normal unfolding of the institution. By virtue of this, the purpose of this research is to identify a proposal for a marketing plan that will increase the profitability of the aforementioned companies in the health sector. The research is exploratory, quantitative and qualitative data are used, as well as interviews and questionnaires that allow obtaining information to establish a proposal. The presented results show that, with the marketing strategy, you can increase the turnover in 2019 by $20 \%$, and increase the number of clients by $20 \%$, in order to obtain a profit and productivity growth to cover
\end{abstract}

\footnotetext{
${ }^{1}$ Universidad Católica de Cuenca, Magister en Administración de Empresas, Cuenca, Ecuador. aemogrovejol406@psg.ucacue.edu.ec

${ }^{2}$ Universidad Católica de Cuenca, Unidad Académica de Administración, Cuenca, Ecuador. klunaa@ucacue.edu.ec

${ }^{3}$ Universidad Católica de Cuenca Sede Azogues, Unidad Académica de Administración, Azogues, Ecuador.jormaza@ucacue.edu.ec

${ }^{4}$ Universidad Católica de Cuenca Sede Azogues, Unidad Educativa Universitaria Católica, Azogues, Ecuador.pgcastrov@ucacue.edu.ec

${ }^{5}$ Universidad Católica de Cuenca, Magister en Administración de Empresas, Cuenca, Ecuador. amtorresb420@psg.ucacue.edu.ec
} 
the regional market. It is concluded that the marketing department of the institution has not done an internal job of dissemination of functions, information and promotions of their services, so they must work on marketing strategies internally.

Keywords: Strategy, marketing, health, hospital, Ecuador

\section{Resumen}

Actualmente el Hospital del Río - Hospirio S.A, es una institución privada que posee la mayor dimensión en edificación y capacidad para albergar pacientes en la región zona 6 de Ecuador, por tanto, los pacientes no solo se encuentran ubicados en el casco urbano de la ciudad de Cuenca, también existen en la zona rural de Cuenca, de la provincia del Azuay y otras provincias tales como Cañar, El Oro, Loja, Morona Santiago y Zamora Chinchipe. Posee instalaciones de primer orden, también cuenta con tecnología avanzada en la rama de medicina para brindar servicios de calidad, con responsabilidad y confianza. Sin embargo, la institución ha tratado de fomentar planes de gestión, para la entrada de pacientes al año, y obtener un flujo de ingresos/egresos, que permitan proyectar su gestión anual, pero el porcentaje entre lo presupuestado y lo real ha tenido diferencias, obteniendo una baja entrada de pacientes, lo que conduce ajustar los gastos para el normal desenvolviendo de la institución. En virtud de ello, el propósito de esta investigación es identificar una propuesta de un plan de marketing que permitan incrementar la rentabilidad de las empresas del sector salud antes mencionado. La investigación es exploratoria, se utilizan datos cuantitativos y cualitativos, así como entrevistas y cuestionarios que permitan obtener información para establecer una propuesta. Los resultados presentados muestran que, con la estrategia de marketing, se puede incrementar la facturación en el año 2019 en un 20\%, y aumentar el número de clientes en un $20 \%$, para así obtener una utilidad y un crecimiento de la productividad para cubrir el mercado regional. Se concluye que el departamento de marketing de la institución no ha realizado un trabajo interno de difusión de funciones, información y promociones de sus servicios, por lo que deben trabajar en las estrategias de marketing a nivel interno.

Palabras clave: Estrategia, marketing, salud, hospital, Ecuador.

\section{Introducción}

El Hospital del Río - Hospirio S.A; es un hospital privado en la ciudad de Cuenca, provincia del Azuay, posee médicos residentes y está en pleno funcionamiento, esta institución tiene en el mercado hospitalario 10 años. 
Es una institución privada con una gran dimensión en edificación y capacidad para albergar pacientes en la región zona 6 , es por este motivo que los pacientes/clientes no solo son del casco urbano de la ciudad de Cuenca, existen pacientes de la zona rural de Cuenca, de la provincia del Azuay y otras provincias como son Cañar, El Oro, Loja, Morona Santiago y Zamora Chinchipe. Además de tener instalaciones de primer orden, también cuenta con tecnología avanzada en la rama de medicina para brindar servicios de calidad, con responsabilidad y confianza de los clientes/pacientes que se atienden en el Hospital del Rio.

Cuenta en la actualidad con instalaciones modernas, amplias, cómodas, fácil acceso, las vías que las circunvalan son de primer orden en la ciudad, cuenta con parqueo amplio para la comodidad de los clientes, además de un pequeño centro comercial en el cual se encuentra locales como farmacias, ópticas, supermercados, bancos, todo esto pensado en el confort que se le puede brindar a sus clientes en un mismo lugar.

La tecnología de punta en todas las ramas de la medicina, hacen que los costos de mantención del hospital también sean altos y se necesita tener un flujo de clientes/pacientes que hagan que las finanzas funcionen acorde al servicio que se brinda actualmente en este hospital.

La administración de la institución durante varios años ha tratado de fomentar planes de gestión, en el cual contengan una estimada entrada de clientes al año, para poder realizar un flujo de ingresos/egresos, y poder proyectar su gestión anual, pero lamentablemente el porcentaje de equivocación entre lo presupuestado y lo real ha tenido altas diferencias, teniendo resultados en contra y una baja en el último periodo de entrada de pacientes.

Cuando se tiene bajo ingreso de clientes/pacientes, el hospital tiene que ajustarse en sus gastos, y los más frecuente es el atraso de pago a los proveedores, demoras en el cumplimiento con entidades financieras, optimización de recursos en todas las áreas de la institución, lo que causan molestias porque no se puede tener las medicinas, productos y recursos necesarios del día al día para el normal desenvolviendo de la institución. Por estos motivos se desarrolla esta investigación, para identificar estrategias de marketing que le permitan elaborar una propuesta que admita mejorar los ingresos monetarios del hospital y optimizar su gestión en todas las áreas y departamentos de la institución, podrá ser más competitivo dentro del mercado en el que se desenvuelve.

Las instituciones de salud tienen una gran responsabilidad de atender al público, el servicio debe brindarse con calidad, con personal especializado en sus áreas, bajo parámetros de eficiencia preestablecidos por cada institución de acuerdo a sus metas planteadas (Falconi del Pozo, 2016). Para poder lograr una atención eficaz se necesita del apoyo de una buena administración que este en concordancia con la planificación estratégica de la institución de salud.

En este sentido, las estrategias de marketing cada día toman más valor, las empresas están orientadas a vender un producto o servicio y para hacerse conocer tienen que emplear las diferentes herramientas de marketing existentes. Así mismo, estas estrategias tienen un valor importantísimo para el avance y su crecimiento, tanto así que 
en un gran número de empresas han independizado los departamentos de marketing, antes estaban fusionados con los departamentos de ventas, se utiliza el marketing como una herramienta para potencializar las ventas.

El objetivo de esta investigación es identificar una propuesta de un plan de marketing que permitan incrementar la rentabilidad de las empresas del sector salud antes mencionado, específicamente en las siguientes áreas: imágenes diagnósticas, laboratorios, hospitalización, unidades de cuidados intensivos adultos, pediátrica y neonatal, y farmacia. La investigación es de tipo exploratoria, se utilizan datos cuantitativos y cualitativos, así como entrevistas y cuestionarios que permitan obtener información para establecer una propuesta, definiendo diferentes estrategias de marketing para mejorar los productos o servicios que ofrecen, con ello la empresa tratará de mejorar su rentabilidad.

\section{Estrategias de marketing. Un estudio desde la gestión empresarial}

El enigma del marketing se refiere a las actividades más antiguas del hombre $\mathrm{y}$, sin embargo, es considerada como la más reciente de las disciplinas empresariales. Para Kotler (2012) el concepto de marketing no es una definición sobre lo que es y hace el marketing, se trata de una forma de pensar, una filosofía de dirección, sobre cómo debe entenderse la relación de intercambio de los productos/servicios de una organización con el mercado, la forma de concebir la actividad de intercambio ha pasado por orientaciones distintas en su evolución, hasta llegar al concepto actual de marketing, en el que se contemplan no sólo las necesidades del individuo sino también, las de la sociedad en general.

Debido a la desaceleración económica, el marketing ha ganado importancia en los últimos años para atraer a los potenciales clientes. En el siglo XXI, esta herramienta administrativa se ha convertido en una de las estrategias clave utilizadas por las organizaciones en todo el mundo. De esta forma, las empresas no pueden usar una estrategia de marketing simple que satisfaga las necesidades tanto de los mercados como de los consumidores, ya que son tan versátiles como para ser tratadas colectivamente, lo que se debe principalmente al cambio continuo en la sociedad moderna (Buil et al. 2012).

Varios autores coinciden que el principal objetivo de las empresas consiste en la maximización de utilidades, y el marketing se ha convertido en la pieza fundamental de toda organización (pública o privada), que se engrana con la planificación organización y control, para de esta manera obtener el éxito esperado contemplado en los objetivos empresarial es a largo plazo.

Por ello, se reconoce que el marketing es una de las razones más importantes para el éxito de cualquier organización. Algunas personas cometen el error de confundir el marketing con la venta, y así visualizan a los clientes siendo "bombardeados" por 
anuncios, en contraposición a esta idea, el marketing real es la creencia de que la sostenibilidad de una empresa se puede lograr satisfaciendo las necesidades de sus clientes mejor que su competencia (Martínez, 2016), de ahí radica su importancia como factor de éxito

La importancia del marketing dentro de las empresas es de vital relevancia para su desenvolvimiento con el fin de alcanzar las metas trazadas. En este sentido, Suárez (2014) hace referencia a ciertos fundamentos de Marketing para la mejora en servicios de salud, esta investigación utiliza escenarios muy similares a los del mercado de salud del Ecuador. Entre las estrategias para cambiar la cobertura del área de salud universal, es el de ampliar, integrar y tener un acceso equitativo enfocado en la excelencia de la atención a las personas y comunidades, el modelo de gestión y atención de las entidades públicas deben ser siempre centrados en las personas.

Los lugares de servicios de salud deben ser accesibles, los pacientes deben acudir de una manera fácil, los horarios deben ser extensos, preferiblemente las 24 horas, deben ser lugares que brinden seguridad, en ciertas áreas privacidad, con una cobertura amplia en todos los ámbitos de la salud, aprovechar al máximo tiempo y espacio para aprovechar la inversión en infraestructura y tecnología (Entrevistas, 2018).

Deben ser de accesibilidad geográfica fácil, tener en consideración que hoy en día mediante el Internet se encuentra las ubicaciones de cualquier centro de salud de manera fácil por medio de algunas aplicaciones de localización. La ubicación geográfica también tiene importancia para sectorizar cantones, parroquias, comunidades en el cual se puede brindar el servicio de salud, es importante tener definido dentro de un plan de Marketing el área que se pretende atender con el servicio que se presta, para en esa área hacer los mayores esfuerzos de Marketing con el fin de atraer al público.

Con esta información, de manera oportuna se podrán hacer las labores de apoyo en la salud y cuidado de enfermedades de la población aledaña al centro de salud, también se puede identificar a tipo de personas, familias que tengan algún tipo de padecimiento para facilitar su traslado y prevención a un centro de salud cercano a la ubicación geográfica.

Entre las variables de importancia de tener una ubicación geográfica determinada y que pueda ser encontrada dentro de aplicaciones del Internet, es el tiempo que se emplea para llegar al tema de atención, el costo que representa su desplazamiento, con esto se minimiza las barreras de accesibilidad y se aprovecha al máximo el tiempo, que en salud es de suma importancia, un minuto puede ser la diferencia en la vida de un paciente.

Una relación idónea de la oferta y la demanda, es el de ubicar a los pacientes con datos demográficos y epidemiológicos, tener la ubicación exacta y saber los centros de salud que hay en esta área y la capacidad instalada de los mismo para poder dirigir a los 
pacientes. El servicio de salud privado tiene cierta ventaja por la comodidad, limpieza y funcionalidad que dan al público en general.

La atención del personal interno del centro de salud es muy importante, la imagen que confiere el personal de salud debe ser de credibilidad, estar constantemente disponible, dispuesto a ofrecer sus servicios con amabilidad, cortesía y respeto, exponiendo su aptitud de servicio hacia el público y el paciente (Tudela y Modol, 2014).

La duración de la espera también puede causar un descontento del paciente, pudiendo dar malas referencias del centro de salud, por eso las cargas de trabajo al personal de atención al cliente de los centros de salud deben ser distribuidas de una manera eficiente, en la que el personal pueda cumplir con sus funciones de una manera normal, sin sobrecargas de trabajo que puede ser nocivo para la salud del paciente, en lo que deriva en una pésima imagen del centro de salud. Este elemento es muy importante, mejor a las otras prestaciones que se ofrecen por que los pacientes son muy receptivos por tratarse de su salud.

Para estar seguros de las diferenciaciones de calidad en las prestaciones de las instituciones de salud, es preferente siempre realizar encuestas de opinión o entrevistas a los pacientes para confirmar que fueron tratados de una manera amable y que los servicios que se les entregó cubrieron sus expectativas. Es importante tener este tipo de estadísticas porque depende de la atención al cliente, la imagen del centro de salud.

Es una realidad que los servicios que se da para el bienestar de una persona, siempre existirán desacuerdos entre las expectativas y las apreciaciones, los establecimientos de salud en varios países están ejecutando encuestas a los pacientes para determinar sus necesidades, considerar sus agrados o desagrados. Los trabajadores del centro de salud deben estar en continua capacitación para aprender prácticas de forma más eficiente de atención al cliente.

La competencia continua en el área de la salud, no deja mucho margen al error a los establecimientos de salud, la calidad tiene que ser un elemento de alto cuidado y estar ligada a cuestiones éticas, no se puede imaginar un establecimiento de salud que no tenga un servicio de calidad desde el punto de vista técnico y profesional. Además, la ética de los empleados debe ser única, un médico, un enfermero, no puede jugar con la vida de un paciente (Tudela y Modol, 2014).

En el área de salud está comprobado que la relación médico-paciente, colaborador de salud-comunidad, es de gran relevancia para la aprobación de un diagnóstico a un paciente, el paciente debe tener la entera confianza en las recomendaciones de su doctor, y además el médico debe disponer de la información adecuada para diagnosticar. La obligación del cliente es cumplir las disposiciones y el tratamiento en la forma que le guiaron, así como la confianza que da al personal que le ofrece algún servicio dentro de una institución de salud, sea este, médico, enfermero facturador, información, secretaria, 
entre otros. En la salud la relación con los colaboradores toma una gran importancia, indudablemente el profesional tiene un liderazgo de opinión, sobre sus pacientes.

\section{Las estrategias de marketing y los ingresos en las instituciones de salud: Una propuesta}

La propuesta de las estrategias de marketing para las instituciones de salud, se realiza con el objetivo de elevar los ingresos en áreas mencionadas anteriormente. Así mismo, el enfoque para realizar dicha propuesta se desarrolla de acuerdo a los elementos del marketing, en este caso factores externos o macro entorno, factores internos o micro entorno, marketing estratégico, marketing táctico y acción/ control.

\section{Factores externos e Internos}

En este sentido, los factores del exterior tienen influencia en la capacidad de la dirección del departamento de marketing para inventar y sostener relaciones beneficiosas con sus clientes metas; estas acciones y factores en ocasiones pueden afectar de manera positiva y en otras veces de manera negativa.

García et al. (2012) consideran que los factores externos del macro entorno son los que pueden ser el medio político-legal; leyes gubernamentales que son un dilema para las instituciones en cual existen diferentes impuestos a pagar, esto conlleva a que el artículo o servicio tiende a aumentar su precio y el cliente final tendrá que cancelar más dinero por el artículo o servicio que va a utilizar. En el ámbito económico se estudian diferentes componentes que podrían perjudicar la adquisición del consumidor, se pueden manejar por medio de indicadores económicos que usan los gobiernos como el tipo de cambio, la inflación, las tasas de interés, entre otras.

Otras variables del macro entorno, son la demografía, economía, naturaleza, tecnología, política y cultura que tienen incidencia en el micro entorno. La empresa y los demás actores participan en un macro entorno más grande de fuerzas que forjan oportunidades y pueden convertirse en amenazas para la institución, entre algunos ejemplos de estas variables del marco entorno están impuestos, políticas internacionales, guerras, terremotos, inundaciones entre otros que hacen que la sociedad cambien ciertos ámbitos de consumo, por lo que las empresas deben estar listas para tener planes de marketing alternativos según los factores macro que pueden influir en un economía de un país.

Ahora bien, un aporte de Rodríguez (2013) considera al micro entorno, como las fuerzas adyacentes a la institución como: compañías, proveedores, consultores de marketing, mercados de clientes, competidores y público que afectan en su capacidad de servir al cliente. Un marketing bien llevado depende de la habilidad para realizar conexiones entre las diferentes áreas de la empresa, los proveedores, los canales de distribución, los clientes, los competidores y los diferentes públicos, los cuales se unifican para establecer el sistema de transferencia de valor de la compañía. 
En la estructura y la organización de un plan de mercadeo es esencial tomar en cuenta la importancia de las variables del marketing interno y externo, se debe considerar que dentro de los objetivos de la empresa debe estar contemplado las necesidades de los trabajadores y/o colaboradores, para que estos se sientan parte de la empresa y desarrollen todas sus cualidades y aptitudes, en el propósito de lograr las metas de la institución de una manera mancomunada; al lograr esta sinergia con los colaboradores, trabajadores darán su mejor esfuerzo para el agrado de los clientes de la empresa, además del empoderamiento y lealtad de los colaboradores hacia la empresa.

A nivel del macro entorno, Ecuador se encuentra en una recesión económica, el estado ha realizado políticas para reducir su tamaño actual, y tener ahorros significativos para poder cubrir brechas en algunos ámbitos sociales y económicos, todo esto ha causado una inestabilidad política en la transición del gobierno anterior con el actual y tras la acusación de desfalcos en muchos contratos públicos, la sociedad se encuentra incrédula ante la política actual del gobierno, dicha inestabilidad ha causado que los inversionistas extranjeros como nacionales vean con mucho riesgo invertir en el país.

Sin embargo, el mercado de salud, por políticas y decisiones adoptadas por el gobierno anterior, el país mejoró en el tema de Salud Pública, haciendo que las instituciones de salud privada inviertan en infraestructura, tecnología y capaciten a sus galenos para entrar en una sana competencia y ofrecer servicios de calidad para poder atraer clientes, pero no solo basta con estas decisiones, también se necesita de la estructuración de un sistema de estrategias mercadológicas integral; para que la sociedad y la zona de influencia conozcan sus servicios, precios, y comodidades que ofrecen.

Al considerar el micro entorno, la propuesta tiene vinculación con la misión, que es entregar cobertura de excelencia en las distintas áreas de la salud, y con la visión, el Hospital del Río se convertirá en un referente de la excelencia en prestación de servicios de salud.

En este sentido se plantean las áreas en las cuales se necesita afianzar, que, a pesar de haber disminuido en sus ingresos, ofrecen servicios completos que son competitivos dentro del mercado de la salud de la zona de influencia, estas áreas son: imágenes diagnósticas, laboratorios, hospitalización, unidades de cuidados intensivos adultos, pediátrica y neonatal, por último, en farmacia. En dichas áreas, de acuerdo a la evaluación realizada, han tenido una baja sobre los ingresos de la institución, por lo que la elaboración de un plan de marketing para el año 2019, va enfocado en la recuperación de estas áreas y el efecto directo en las finanzas de la empresa, como se observa el servicio en las áreas de bajo rendimiento tienen una gran inversión a nivel de infraestructura, tecnología y recurso humano.

Así mismo, se realiza un análisis FODA como un análisis institucional de la empresa, con todas las variables descritas para realizar el Plan de Marketing. 
Gráfico 1. Análisis FODA

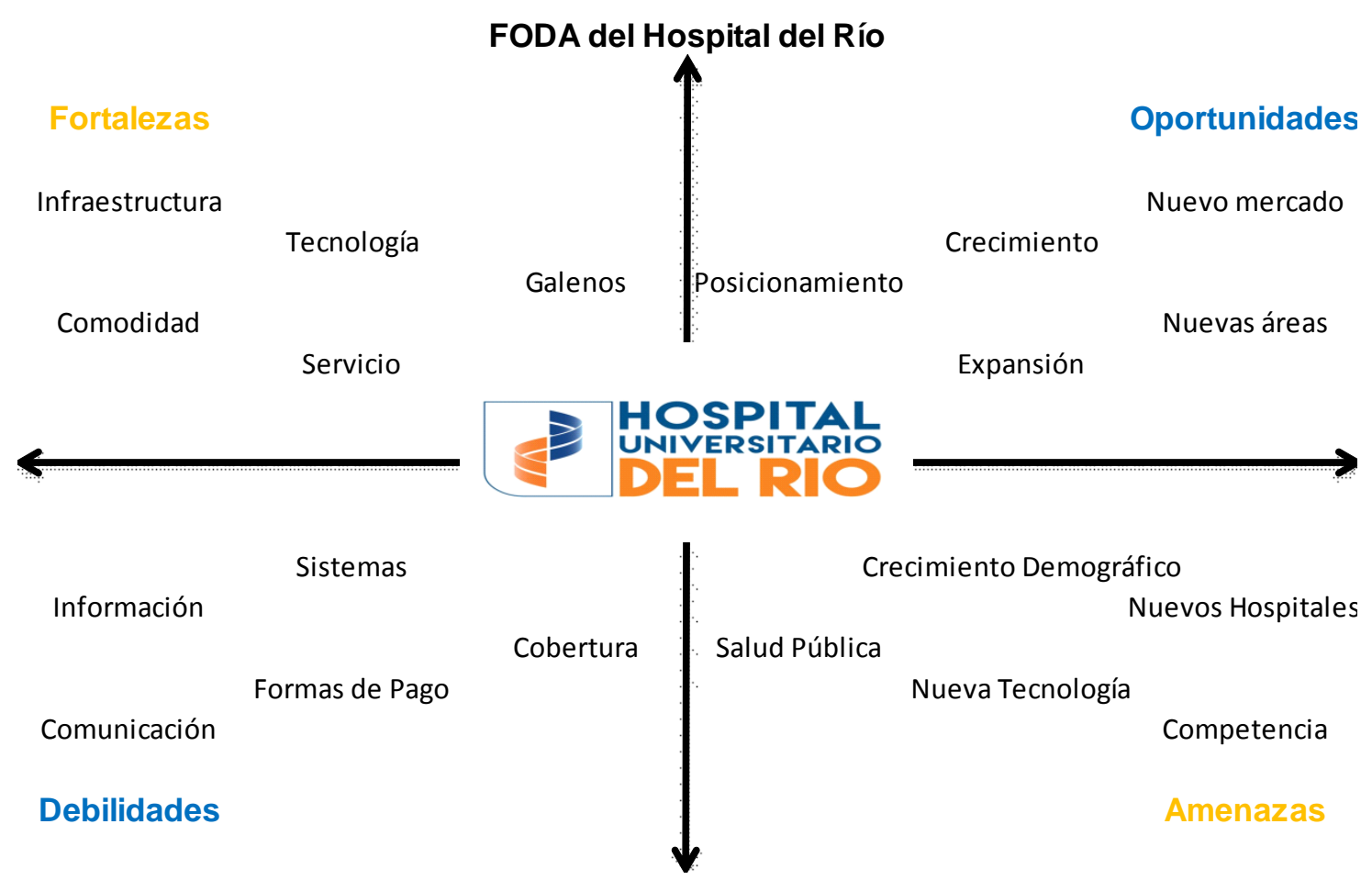

Fuente: Elaboración propia

\section{Marketing Estratégico}

El marketing estratégico es una metodología de análisis y conocimiento del mercado, con el objetivo de detectar oportunidades que ayuden a la empresa a satisfacer las necesidades de los consumidores de una forma más óptima y eficiente, que el resto de competidores. En este sentido se analiza el consumidor, el mercado, posicionamiento del producto y la promoción y las estrategias las mismas.

\section{Consumidor}

En la empresa se diferencia al paciente y cliente, el paciente es aquel que llega atenderse en las instalaciones del hospital, y cliente es aquel que paga por la atención del paciente, en muchos casos el paciente puede ser el mismo cliente, pero en muchos casos no, como por ejemplo cuando se atiende un niño y la factura es pagada por sus padres o representantes, de igual manera cuando un paciente entra por un seguro privado o por medio de la red pública de salud, los pacientes no pagan a la institución sino los aseguradoras o las empresas públicas.

Las costumbres en el mercado de la salud en Cuenca han ido variando en el tiempo, hace 12 años atrás, la salud pública se veía como lo peor dentro de la atención, y 
muchos optaban por la salud privada, buscaban formas de financiarse el atenderse en hospitales privados, ya que en lo público no encontraban respuestas a sus necesidades, el Ministerio de Salud Pública en el Gobierno, implementó estrategias e invirtió en la Salud Pública, haciendo que sus hospitales entreguen atención de primera y con tecnología, esto llevó a que los consumidores o pacientes del área de salud tiendan a buscar la salud pública.

Al tener este fenómeno la demanda a estas instituciones, superó su oferta, por lo que, dentro de las decisiones de las autoridades de la salud en el Ecuador, tomaron la decisión de transferir pacientes de la salud pública a la salud privada, corriendo con los gastos el MSP o el IESS, dependiendo de qué institución realice la transferencia.

En los últimos años, nuevamente la salud pública ha sufrido reveses por temas de corrupción y falta de medicinas en sus dependencias, por lo que nuevamente han tomado auge los hospitales privados, además que en un target socio económico de una clase media alta, prioriza factores como la comodidad, y la atención personalizada, con respuestas inmediatas a sus solicitudes, haciendo que la demanda de estas instituciones de salud privada tenga un nuevo posicionamiento desde hace dos años.

\section{Mercado}

Con datos recopilados del departamento de atención al cliente del Hospital del Río del año 2016 se obtuvo que el mercado de la salud en la ciudad de Cuenca fue de 1.105.000 pacientes, tomando datos del Instituto Ecuatoriano de Estadísticas y Censos (INEC), sobre demografía y población, se puede proyectar el mercado de la salud para el año 2019.

Si se toma que el crecimiento por año es de 2,09\% al 2016 se tendría un crecimiento demográfico del 12,52\%, lo que significa una población estimada de 674.600, con esos datos el mercado de salud de Cuenca, bordaría los siguientes números de pacientes:

Tabla 1. Proyecciones del Mercado de Salud

\begin{tabular}{cccc}
\multicolumn{4}{c}{ Proyecciones del Mercado de la Salud } \\
\hline Año & Habitantes & Pacientes & \% Densidad Pacientes \\
\hline 2016 & 674600 & 1105000 & $63,80 \%$ \\
2019 & 845848 & 1644658 & \\
\hline
\end{tabular}

Fuente: Departamento Atención del Cliente Hospital del Río.

Con la estimación del mercado de la salud en Cuenca para el 2019, y con los parámetros dados, en el cual se enumeró los objetivos o metas para el 2019, se puede estipular que 
son objetivos alcanzables si se hace un marketing focalizado en los potenciales clientes del Hospital del Río, se necesita atraer un total de 22.000 pacientes más, de un crecimiento del mercado de 539.658, el objetivo de incrementar la facturación en 2.724.448 dólares, daría un promedio de facturación por paciente de 123,83 dólares, metas totalmente alcanzables.

La competencia directa del Hospital del Río en la ciudad de Cuenca en el mercado de salud privada son los Hospitales Monte Sinaí y el Hospital Santa Inés, ambos hospitales están ubicados dentro del casco urbano de la ciudad en una zona de crecimiento muy importante, los dos hospitales han aumentado la infraestructura, el limitante es estar en zonas de población alta, no tienen ya mucho lugar de expansión, entre sus fortalezas esta la cercanía a toda la periferia urbana de la ciudad, que también se puede convertir en una amenaza, teniendo en cuenta que hay pacientes que necesitan lugares de tranquilidad para su descanso, y al estar situados en pleno casco urbano tienen los problemas de ruido y smog.

Las características de los servicios que van estar incluidos en el plan de marketing 2019, son de calidad de acorde a las mayores exigencias en el mercado de la salud, cuenta con la tecnología y la infraestructura para brindar los servicios que garanticen una buena atención a sus pacientes, con referencia al mercado estos servicios necesitan posesionarse dentro de la población y que la primera alternativa en el área de salud sea el Hospital del Río.

Las instalaciones del Hospital del Río, ofrecen comodidad, tranquilidad a sus pacientes en la infraestructura más grande en el Austro del Ecuador, garantiza una estadía confortable a sus acompañantes, recordando que un enfermo nunca está solo, y que la tranquilidad de su o sus acompañantes es importante para que estén en calma, puedan ser una verdadera compañía y apoyo para el paciente internado.

La diferenciación del Plan de Marketing 2019 que se va a presentar en esta investigación para el Hospital del Río, es que esta publicidad vaya dirigida a las cinco áreas ya descritas de la institución y estén segmentados, por edad, estacionalidad, nivel económico y pacientes con diferentes gravedades en sus enfermedades o lesiones.

\section{Posicionamiento del servicio}

El Hospital del Río, con sus activaciones de Marketing posesiona sus servicios de salud en la población cuencana, promocionando que, para desarrollar cualquier proyecto en la vida, lo primordial es tener buena salud. Con la propuesta del plan de marketing del 2019 se intenta que esta imagen llegue a más sectores y potencializar a posibles clientes no solo de Cuenca, sino de todo el Austro.

\section{Promoción y Estrategias}

En este punto se da a conocer las estrategias de marketing para el 2019, su público objetivo, quienes van estar a cargo de la promoción, el vigilar diseños estructurados que 
deben ir en las redes sociales y el material Point of Purchase (POP), una vez que este ejecutándose el plan, identificar a los encargados de la dirección y control.

El público objetivo es la población económicamente activa, de la Zonas 6 y 7 del Ecuador, que tengan alguna dolencia, o necesiten de chequeos de prevención de una institución de salud, sin discriminación de edad, sexo, raza o nivel económico.

Las áreas en las cuales se va a focalizar el Plan de Marketing 2019 son: imágenes diagnósticas, laboratorios, hospitalización, unidades de cuidados intensivos en las áreas de adultos, pediátrica y neonatal, por último, en farmacia, Como un punto importante se resalta que el marketing debe comenzar con el personal interno de la empresa quienes deben estar enterados de las diferentes acciones que el departamento de marketing está programando.

En la siguiente tabla por áreas se da a conocer las estrategias de marketing que se utilizarán, tanto de manera interna, como al público externo:

Tabla 2. Estrategias de Marketing para el Hospital del Río

\begin{tabular}{|c|c|}
\hline Área & $\begin{array}{c}\text { Estrategia de } \\
\text { Marketing }\end{array}$ \\
\hline $\begin{array}{l}\text { Todas los departamentos } \\
\text { internos del Hospital del Río }\end{array}$ & $\begin{array}{c}\text { Marketing Interno por medio } \\
\text { de información por los correos } \\
\text { institucionales; para que el personal } \\
\text { interno del Hospital del Río sepa de } \\
\text { las campañas de Marketing de la } \\
\text { institución }\end{array}$ \\
\hline Imágenes Diagnosticas & $\begin{array}{c}\text { * Marketing Digital (redes sociales) } \\
\text { * Marketing Tradicional POP }\end{array}$ \\
\hline Laboratorios & $\begin{array}{c}\text { * Marketing Digital (redes sociales) } \\
\text { * Marketing Tradicional POP } \\
\text { * Marketing de Precios }\end{array}$ \\
\hline Hospitalización & $\begin{array}{c}\text { * Marketing Digital (redes sociales) } \\
\text { * Marketing Tradicional POP } \\
\text { * Marketing de Precios }\end{array}$ \\
\hline $\begin{array}{l}\text { UCI Adultos } \\
\text { UCI Pediátrica } \\
\text { UCI Neonatal }\end{array}$ & $\begin{array}{c}\text { * Marketing Digital (redes sociales) } \\
\text { * Marketing Tradicional POP } \\
\text { * Marketing de Precios } \\
\text { *Marketing de Diferenciación }\end{array}$ \\
\hline Farmacia & $\begin{array}{c}\text { * Marketing Digital (redes sociales) } \\
\text { * Marketing Tradicional POP } \\
\text { * Marketing MIX (plaza, precio, } \\
\text { producto, promoción) }\end{array}$ \\
\hline
\end{tabular}

Fuente: Elaboración Propia 
En cada una de las áreas se plantea un estrategia de marketing acorde a su destino de llegada, como se puede observar en todas, salvo el marketing interno, se utiliza redes sociales que hoy en día es un instrumento indispensables para dar a conocer los servicios de la institución, promociones, eventos, el Hospital del Río debe invertir, en redes sociales para que esta información no solo llegue a un radio de acción de la provincia del Azuay, en la propuesta se propone que llegue a las capitales de provincias de la zona austro.

En la actualidad la institución ya tiene esta herramienta, que es manejada de una manera aceptable por el departamento de marketing de la institución lo que se busca es que se invierta para que la información de las redes sociales llegue a más público y por ende a más clientes potenciales. Es necesario dar a conocer las plataformas actuales en redes sociales que garanticen el mejor manejo del Marketing de la institución.

\section{Marketing Táctico}

Consiste en planificar las actividades reales que mejoren el posicionamiento competitivo y que transmitan una imagen de marca adecuada. El marketing estratégico es la idea. El marketing táctico es la acción y aplicación de dicha idea. Como elementos del marketing táctico se consideran los servicios y la inversión y financiación

\section{Servicios}

Los prestadores de servicios deben interactuar eficazmente con los clientes para crear un valor superior durante los encuentros de servicio. La eficacia de la interacción, a su vez, depende de la habilidad de los empleados de primera línea y de los procesos de producción y apoyo del servicio que respaldan a estos empleados.

A lo largo de los 10 años de la vida institucional del Hospital del Río, se ha caracterizado por entregar servicios médicos de calidad a la ciudadanía cuencana y de la Provincia del Azuay, se ha ganado su participación del mercado hasta llegar hacer la institución número uno en servicios de salud privados, pero aun así por el tamaño de su infraestructura, y toda las instalaciones que existen en su edificio, no está aún explotado al máximo de su capacidad, por tal motivo sus costos de mantención son altos, por lo que se necesita la afluencia de más pacientes.

La marca del Hospital del Río, ya ha ganado adeptos en Cuenca, tiene un prestigio y ha ido creciendo durante su tiempo de atención, y de la misma manera que la ciudad de Cuenca ha crecido en su población y en su economía la institución también debe acoplarse a estos crecimientos, trabajar por captar nuevos clientes y expandirse en el mercado. 


\section{Inversión y Financiación}

El Hospital del Río ya cuenta con un departamento de marketing, debidamente estructurado y con la infraestructura necesaria para cumplir sus funciones, las diferentes estrategias de marketing planteadas, los métodos y medios de hacer llegar el contenido de estas estrategias a los potenciales clientes de la empresa en todas las zonas de influencia, en la ciudad de Cuenca, los cantones de la provincia del Azuay, y las provincias aledañas como Morona Santiago, Loja, El Oro y Cañar. Se han obtenido los siguientes costos referenciales de elaboración de flayers, roll up, vallas, conseguir bases de datos para él envió de correos institucionales / mensajes de texto, el pautar en radio y televisión, y el pago mensual que se hace a instrumentos de redes sociales. Se ha elaborado el siguiente cuadro de presupuestos para el plan de marketing del Hospital del Río para el año 2019.

Tabla 3. Presupuesto de Marketing Hospital del Río año 2019

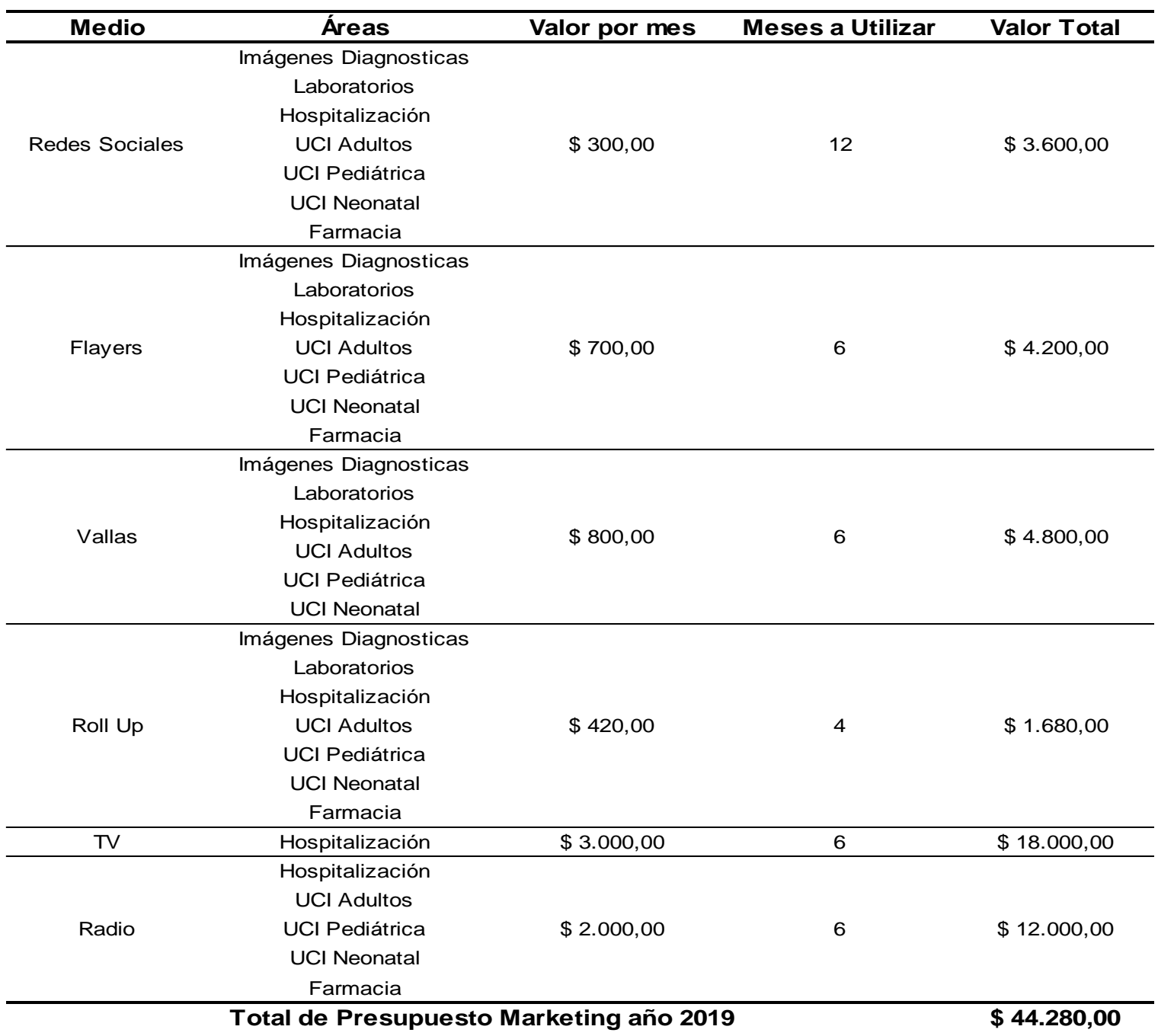

Fuente: Elaboración Propia 
Están estipulados precios de trabajos y pautas de acorde al nivel social que se requiere llegar, target medio alto, ciertos medios son por períodos en fechas en la que hay una gran demanda por cualquiera de las áreas de la salud, como se explicó en párrafos anteriores, fechas estacionales como feriados, entrada a clases, fiestas internas de cada ciudad, temporadas de frío o calor, y así algunas variables externas que empujan que hayan períodos en que la demanda por instituciones de salud suban en un período determinado.

La financiación del plan de marketing 2019, debe estar dentro del plan operativo anual (POA) de la institución, y se debe tomar del porcentaje de utilidades del año 2018, en la cual la utilidad antes de impuestos sería de 1.953.924 dólares, el presupuesto del plan de marketing es de 44.280 dólares, lo que significa el 2,27\% de las utilidades, si se toma como referencia lo que el plan de marketing contribuiría en subir los ingresos en el año 2019 por un valor de 2.724.448 dólares, el resultado de inversión del plan de marketing es apenas de un $1,6 \%$.

El valor total de los 44.280 dólares, no son erogados inmediatamente, se debe realizar un plan de financiación con los proveedores, además de existir la posibilidad de hacer cruces o canjes publicitarios con algunos proveedores de los servicios de los medios de marketing, como por ejemplo, un canje de publicidad con empresas televisivas, pautaje en televisión versus servicios de exámenes médicos en todas las áreas de los empleados de la empresa televisiva, y así negociar con algunas empresas, para que exista la contraparte no solo del egreso, sino también del ingreso y ver desde una primera instancia el regreso de la inversión.

Otro tema a tener en cuenta para el ahorro del presupuesto referencial, es trabajar con cotizaciones de por lo menos tres proveedores en el material POP, como es volumen se puede obtener rebaja de precios, y bajar el presupuesto referencial.

El plan de marketing 2019 no contempla inversiones de inmediata resolución, como pueden ser apoyo a simposios médicos, a temas de salud y deporte, organización de seminarios de galenos reconocidos dentro del mercado de la salud, a instituciones de niñez, entre otros que causan también efectos de reciprocidad por parte de la sociedad hacia la institución que patrocina este tipo de eventos, cuyo financiamiento debe ser extra presupuestario.

\section{Acción y control}

Los resultados financieros que se espera lograr con la implementación del plan de marketing 2019, en forma resumida son los siguientes: 
Tabla 4. Análisis de rendimientos financieros para el año 2019

\begin{tabular}{ccccccc}
\hline Año & No. Pacientes & Crecimiento & Ingresos & Crecimiento & Utilidad & Crecimiento \\
\hline 2016 & 110000 & & & & & \\
2018 & & $20,00 \%$ & $\$ 13.622 .240$ & $20,00 \%$ & $\$ 1.953 .924$ & $38,00 \%$ \\
2019 & 132000 & & $\$ 16.346 .688$ & & $\$ 2.696 .415$ & \\
\hline
\end{tabular}

Fuente: Elaboración Propia

De acuerdo con los rendimientos financieros a invertir se espera el incremento de pacientes por provincias, lo que sirve de guía para la inversión por sectores. Así mismo, se espera un retorno sobre la inversión, la cual será tomada de la rentabilidad del 2018 y se pretende un retorno significativamente atractivo si se aplica el plan de marketing propuesto.

\section{Conclusiones}

Dar importancia en el plan de marketing 2019 a las zonas de influencia que tiene Cuenca como ciudad eje del Austro del Ecuador, donde se puede hacer publicidad para atraer pacientes. Trabajar en forma focalizada el plan de marketing en las áreas que han tenido una baja producción en los años 2015 - 2017 que son; imágenes, laboratorios, hospitalización, unidad de cuidados intensivos y farmacia. Comenzar con el marketing interno, es decir considerando el personal de la institución que son potenciales clientes, que los empleados sean los portavoces dentro de la institución, con sus familiares y amigos de los servicios, beneficios y promociones de la institución.

Promociones semanales en las áreas de baja producción, por medio de redes sociales para hacer activas y de constante interacción entre los usuarios y el departamento de marketing que envía la segmentación de las diferentes informaciones de las redes sociales de la institución. Énfasis en que la institución trabaje con otras formas de pago, así como con aseguradoras, para coordinar el cubrir costos en forma equitativa. Que el departamento de atención al cliente monitoree el regreso de la inversión del plan de marketing por medio de encuetas a los clientes y pacientes del Hospital del Río durante al año 2019, para poder mantener un sistema de información y lograr los objetivos propuestos. 


\section{Referencias bibliográficas}

Buil, I., Melero, I., y Montaner, T. (2012). La estrategia de marketing con causa: Factores determinantes de su éxito. Universia Business Review (36), 90-107.

Falconi del Pozo, A. M. (2016). Estructura organizacional del área administrativa de una clínica privada de especialidad. Quito, Ecuador: Universidad San Francisco de Quito - Colegio de Postgrados.

Ferell, O., y Hartline, M. D. (2006). Estrategias del Marketing. México D.F., México: Thomson.

Hospital del Río. (2016). Estado de Resultados Comparativos Ejercicio Fiscal 2016. Cuenca: Departamento de Contabilidad Hospital del Río.

Kotler, P., \& Keller, K. (2012). Dirección de marketing. México D.F.: Pearson Educación.

Martínez, D. (2016). Factores clave en marketing: enfoque de empresas de servicios. Orbis. Revista Científica Ciencias Humanas, 12(34), 42-58.

SENPLADES. (2017). Plan Nacional de Desarrollo "Toda Una Vida". Quito, Ecuador: Secretaría Nacional de Planificación y Desarrollo.

Suárez, N. (2014). Enfoque social de la mercadotecnía y los desafíos de la cobertura universal en salud. Revista Cubana de Salud Pública, 41(1), 1-11.

Tudela, P., y Modol, J. (2014). La Saturación en los Servicios de Urgencias Hospitalarias. Emergencias 2015, 27, 113-120. Recuperado de http://formacionemergencias.portalsemes.org/formacion/pdf/2015_1_semestre/s aturacion_servicios_urgencias_hospitalarios.pdf

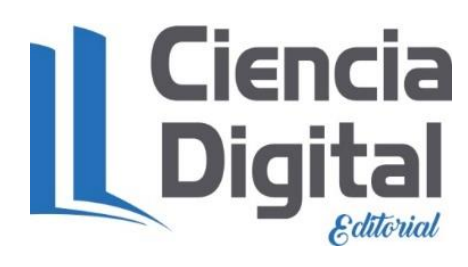




\section{PARA CITAR EL ARTÍCULO INDEXADO.}

Mogrovejo Lazo, A., Luna Altamirano, K., Ormaza Andrade, J., Castro Vazquez, P., \& Torres Beltrán, A. (2019). Plan de marketing en el sector salud. Ciudad de Cuenca, Ecuador. Ciencia Digital, 3(2.3), 5-22.

https://doi.org/10.33262/cienciadigital.v3i2.3.483

\section{\Ciencia}

El artículo que se publica es de exclusiva responsabilidad de los autores y no necesariamente reflejan el pensamiento de la Revista Ciencia Digital.

El artículo queda en propiedad de la revista y, por tanto, su publicación parcial y/o total en otro medio tiene que ser autorizado por el director de la Revista Ciencia Digital.
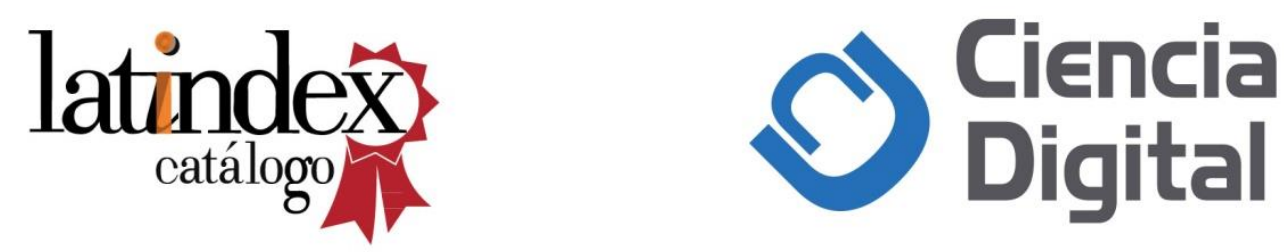